\title{
AUTONOMIA DA MULHER À LUZ DA CRIAÇÃO HUMANA
}

Carliane de Oliveira Carvalho ${ }^{1}$

CARVALHO, C. de O. Autonomia da mulher à luz da criação humana. Rev. Ciênc. Juríd. Soc. UNIPAR. Umuarama. v. 19, n. 2, p. 129-141, jul./dez. 2016.

RESUMO: A questão do aborto necessita de uma análise ampla que deve envolver aspectos em que a sociedade deve participar, a individualidade humana afeta ao âmbito familiar e a autonomia da mulher, para assim alcançar a concepção da liberdade individual e jurídica da mulher a respeito do tema.

PALAVRAS-CHAVE: Aborto; Autonomia social; Autonomia familiar; Autonomia individual.

\section{INTRODUÇÃO}

A proposta desse texto é apresentar uma pequena reflexão acerca da questão conceitual da autonomia feminina com base na situação do aborto, sob a perspectiva da criação humana e sua finalidade social. A despeito de parecer um problema com solução na experiência, em verdade, é tema que discute conceitos e estruturas de ampla repercussão empírica. A linha argumentativa eleita requer a predefinição de questões diretamente relacionados à autonomia e à necessidade de estudo do tema, para a compreensão do alcance na estrutura social.

A primeira das questões é a autonomia social, a partir da investigação da integralidade do corpo social e das implicações da autonomia individual e sua repercussão na autonomia social, mais especificamente, qual a implicação da autonomia feminina para a autonomia do todo.

A segunda questão a ser pontuada é o momento social no qual as lutas políticas femininas se intensificaram e adquiriram relevo, ao ponto de hoje representarem forte expressão do multiculturalismo ${ }^{2}$.

Após estabelecidas essas premissas, passar-se-á à investigação da questão eleita, a extensão da criação humana, a quem cabe decidir sobre a criação (nascimento, vida e morte) de uma pessoa. Acerca desse aspecto, elegeu-se três hipóteses para a análise argumentativa.

DOI: https://doi.org/10.25110/rcjs.v19i2.2016.6464

${ }^{1}$ Procuradora Federal - Procuradoria Geral Federal/Advocacia Geral da União. Doutoranda e Mestre em Direito Público pela Universidade Federal da Bahia. Especialista em Direito Processual Civil. Graduada em Direito pela Universidade Federal da Bahia-UFBA. Professora de graduação e pósgraduação em Direito do Estado, com ênfase em Direito Constitucional e Administrativo.

${ }^{2} C f$. HALL. Stuart. A identidade cultural na pós-modernidade. $10^{\mathrm{a}}$ ed. Rio de Janeiro: DP\&A editora, 2005. 
Não se almeja verificar todas as possíveis implicações do tema na vida social, de modo que não se tem uma apresentação de elementos finitos, mas apenas de subsídios trazidos a título exemplificativo quanto à extensão da criação na atual sociedade brasileira.

A primeira dentre as possibilidades é verificar se a criação teria por destino a sociedade, o que implicaria na necessidade de toda ela participar da integralidade das fases de criação do indivíduo. A segunda, se seria um processo decorrente da individualidade humana, afeta ao âmbito familiar, de modo que caberia aos pais, em conjunto, decidirem sobre todo o processo de criação. A terceira, se representaria a extensão da liberdade individual, especificamente a liberdade da mulher, cabendo a ela, estritamente, a decisão quanto ao processo inicio, meio e fim - da criação.

\section{AUTONOMIA SOCIAL ${ }^{3}$}

Inicialmente, procurou-se definir aquilo que é social, como se compõe e se estabelece a fim de, então, analisar a tão cotejada autonomia. A sociedade é a instituição a ser investigada, perquirindo acerca do porquê da necessidade dela ao homem.

Sendo a sociedade uma instituição, Cornélius Castoriadis concebe a teoria da instituição a partir do olhar humano interrogativo para a coisa que observa, de modo que, se o homem encontra-se dentro da coisa, o olhar já se inicia comprometido, pelo contexto e demais instituições que compõem e formam a sociedade verificada, na qual o investigador se insere, especialmente, a instituição da linguagem (CASTORIADIS, 2004).

Dessa premissa, conclui-se que é necessário um mínimo de afastamento do objeto estudado, tornando imprescindível a ruptura histórica com a sociedade, libertando os indivíduos investigadores das amarras de contexto, conferindo-lhes a possibilidade de usar meios de pesquisa livres e de interrogação ilimitada (Id. Ibid). A liberdade de pensamento questiona a verdade quanto à existência de justiça do poder estabelecido e das leis; de modo que, cada símbolo linguístico das assertivas até então verdadeiras, devem ter seu conteúdo e estrutura submetidos à comprovação de estabilidade (Id. Ibid).

As sociedades expõem as concepções delas próprias (CASTORIADIS, 1982), portando em si "significações que se desencadeiam em totalidades em si mesmas significantes" (Id. Ibid). Isso porque "a evolução não é 'autônoma' em nenhum sentido, mesmo o mais superficial deste termo" (Id. Ibid), ao mesmo

${ }^{3}$ Trata-se de tema já abordado por nós em: $C f$. CARVALHO, Carliane de Oliveira. O Supremo Tribunal Federal e a falácia democrática: proposta de composição e processo. Salvador-BA: Editora Dois de Julho, 2015, p. 41-77. 
tempo em que a "“unidade dialética' da história é um mito" (CASTORIADIS, 1982, p. 56-57).

Citado autor aproxima-se da linha investigativa de Karl Popper, ao refutar a evolução histórica de uma única sociedade humana, questionando a conexão entre os povos da mesma linha histórica, pois o investigador atua como colecionador (POPPER, 1974) de fatos, escolhendo aqueles que interessam para a solução (ou fim desejado). Sendo assim, já influenciado pelas estruturas de significados e símbolos do contexto em que se insere.

As instituições são, como extensão do indivíduo (GRAMSCI, 1976), desejadas e queridas, a questão conflitante se encontra na definição acerca do limite de atuação delas em confronto com a autonomia do sujeito. Há um desejo paradoxal entre a autonomia e a responsabilidade, refletindo uma vontade consciente, "que ao mesmo tempo eles interiorizem essas instituições e possam julgá-las como se não as tivesse interiorizado" (CASTORIADIS, 1999, p. 224).

Para Calmon de Passos, "somos, assim, liberdade, que se realiza, porém que, para realizar-se como tal, paradoxalmente, tem que se deixar limitar, possibilitando a realização da liberdade do outro, sob pena de inviabilizar qualquer liberdade" (PASSOS, 1999, p. 17-18).

Desse modo, faz necessária uma educação pela qual o indivíduo possa julgar as instituições que são reflexos de seu desejo autônomo. Sociedade autônoma é aquela capaz de permitir a autoreafirmação do sujeito como sujeito individual social, podendo exercer um poder crítico de reafirmação das instituições reflexo dos atos conscientes por ele praticados, mas que não os aliene (CASTORIADIS, 2007, p. 224-225).

Cornelius Cartoriadis entende que é possível falar num imaginário social ou numa sociedade instituínte concebida na e pela posição de significações imaginárias sociais e da instituição, sendo a instituição a "presentificação" das significações instituídas. Concebe-se uma imaginação radical associada à presentificação de sentido como reflexo "das condições identitárias-conjuntistas do representar/dizer-social” (CASTORIADIS, 1982, p. 414).

Para Rosemiro Pereira Leal, a concepção evolutiva única estabelece uma sociedade-fantasma (LEAL, 2010, p. 137), de modo que a liberdade investigativa impõe o rompimento da concepção do Estado como lugar de iguais em affectio-societatis, progressivamente alcançada com o simples fluir das eras, e que tem como confirmação o reger-se por uma constituição (Id. Ibid).

Citado autor defende a necessidade de se garantir a formação da vontade balizada por uma teoria linguística por meio da qual a todos os interessados seja garantido o contraditório; sendo essa condição de definição de seu destino (debater seu próprio delírio) o que confere ao homem a qualidade de humano (LEAL, 2010). 
Para tanto, é necessário viabilizar a desconstrução por meio de discussão crítica, com a confrontação dos conceitos até então inquestionáveis da dogmática analítica, a fim de se instaurar "via construtiva da democracia numa visão de pós modernidade não paideica" por uma ciência não dogmática do direito (LEAL, 2013, p. 10-11).

O paradigma linguístico dialógico é processo definido por meio da Teoria Neoinstitucionalista do Direito, pensada em níveis instituínte, constituinte e constituído do processo, por meio de estruturas pré-estabilizadas constitucionalmente, resultantes do direito fundamental ao contraditório, à liberdade dis-cursiva e à dignidade (LEAL, 2010).

Uma sociedade autônoma deve conceber-se aberta à possibilidade de construção e desconstrução normativa do direito por meio de seus representados, na medida em que pode não mais refletir os interesses da sociedade como um todo. O reconhecimento da lei, atributo da autonomia social, tem por base estruturante a possibilidade da destruição dela por todos, quando não mais espelhar os anseios sociais.

A hermenêutica-isomênica, tratada por Rosemiro Pereira Leal, garante a igualdade de argumentação e interpretação para todos, com conteúdo fixado na "coisa julgada constituinte", na prévia interpretação resguardadora da igualdade de contraditório dentro da relação processual (LEAL, 2013, p. 11).

Para referido autor, em um Estado democrático deve ser oportunizado a todos os destinatários das normas a completa igualdade, inclusive interpretativa. Assim, "haverá a ampliação do ideal de cidadania, uma vez que todas as pessoas são vistas e abordadas como cidadãs, desenvolvendo o sentimento comum de pertencimento à sociedade" o que pode favorecer o respeito aos direitos humanos (CARVALHO, 2014).

Para a formação e exercício da cidadania, Wilson Alves de Souza destaca a essencialidade do processo em que "a democracia substancial é, nada mais nada menos, a aplicação efetiva do princípio democrático por um determinado sistema democrático" (SOUZA, 2008, p. 59). Nesse ponto, as teorias apresentadas convergem quanto à necessidade da definição de uma técnica permissiva e garantidora da realização da democracia.

No Brasil atual, a configuração de democracia refere-se a um povo integralizado pelo atributo da autodeterminação, o que impõe ao Estado o poder-dever de garantir e oportunizar a representatividade política e, principalmente, o debate público realizador das decisões sociais (SALGADO, 2007), pois a "proposta constitucional é sua transformação em Sociedade Jurídico Política Democrática de Direito pela possibilidade cognitiva de todos no espaço processual" (LEAL, 2013, p. 54). 


\section{A LUTA DO FEMINISMO}

A necessidade de estudo das minorias, destacadamente da feminina, decorre da própria definição de sociedade adotado, como um todo que tem potencial de concretizar, por debate público, as decisões sociais, compondo-se por individualidades que se sentem refletidas na sociedade, na medida em que ratificam ou não, permanentemente, as instituições, suas estruturas e conteúdo.

Dentre tantas minorias que poderiam aqui ser citadas, elege-se a feminina pelo alto quantitativo de integrantes na composição numérica do todo social (BRASIL, 2006) e, também, como Destacou Stuart Hall, em razão das consequências advindas das reivindicações feministas, sobretudo, no que se refere às dimensões objetivas e subjetivas da política, e na inquietação quanto ao reconhecimento da "identidade social de seus sustentadores", politizando questões que até então eram tidas como pessoais (HALL, 2005, p. 43-45).

A autonomia do todo social pressupõe a autonomia das individualidades que o compõe. É inepto conceber uma sociedade autônoma, quando os integrantes dela não possuem meios decisórios reais, ao passo em que não lhes é permitido a auto-reafirmação institucional enquanto sujeito individual social ("eu me requero"), não exercendo poder crítico de reafirmação das instituições reflexo dos atos conscientes por eles praticados (CASTORIADIS, 2007). Antes mesmo, não se pode falar em reafirmação das decisões sociais, se não houve decisão quanto ao ato primeiro de criação, quando é retirada de seu destinatário a possibilidade de participação instituínte original das decisões políticas da sociedade.

Estabelecida a importância da questão, elegeu-se o tema da criação humana em sua extensão para abordar a autonomia feminina, limitando-se os aspectos temáticos a serem abordados, em virtude do entrave espacial do capítulo.

\section{EXTENSÃO DA CRIAÇÃO HUMANA}

\section{1 ÂMBITO SOCIAL}

A primeira hipótese conceitual estudada é aquele segundo a qual a criação é um ato em que toda a sociedade tem responsabilidade, desde a decisão quanto ao nascimento, passando pela criação e condução dos princípios educacionais, a utilidade humana na sociedade, até a não mais serventia do indivíduo ao grupo.

Esse tipo de concepção pode ser encontrado em sociedades que possuem finalidade múltiplas, de cunho mais simplificados, dispondo para a consecução de seus fins de estrutural organização quanto às atribuições individuais de seus integrantes, o que se pode observar nas sociedade tribais.

A cidade antiga de Esparta, por exemplo, dedicava-se como fim estatal 
à defesa e extensão bélica de seu território, ou seja, à guerra. Os indivíduos que nasciam e que passavam a integrar a comunidade tinham de possuir condições físicas para expressar a arte da guerra, contribuindo para o fim social. Por isso, crianças que apresentassem características físicas impeditivas do aprendizado da arte belicosa eram imediatamente descartadas, pois não serviam à sociedade e ao fim estabelecido por ela (FERREIRA, 2010).

Nessa primeira situação, nota-se que a decisão por uma finalidade social a ser preservada é superior a qualquer ideia de preservação de interesses individuais. A estrutura de individualidades não é compatível com a formação social. A título de deixar mais clara a questão, nesse tipo de sociedade a função a ser desempenhada pelo indivíduo é disposta conforme a necessidade social e não a vontade particular dele. ${ }^{4}$

Se o indivíduo inservível socialmente, segundo a finalidade do grupo, não for afastado, toda a sociedade se comprometerá em sua própria existência. Assim, um integrante que não contribui para o sustento do grupo, representará mais trabalho aos demais, e, gradativamente, pode implicar em fadiga social. Um indivíduo que não guerreia e nem se protege em uma comunidade belicosa atrasará a movimentação do grupo, pois requererá proteção especial, podendo enfraquecer a estratégia de guerra, culminando na extinção da própria sociedade.

Por razões como as apresentadas, nesses modelos sociais, a possibilidade de aborto relaciona-se com a estrutura conceitual que a instituição apresenta. Há casos de aborto legitimado socialmente, para controle populacional, e há casos de exclusão do indivíduo do seio grupal, guando ao nascer se identifica que é inservível à finalidade social; exclusão que pode se dá por meio da morte.

Em tal sociedade, a liberdade individual, no aspecto aqui analisado, é ínfima, ou até inexistente; de modo que, em razão da finalidade máxima a que a sociedade serve, é que seus indivíduos terão seus destinos definidos, inclusive quanto à própria vida, pois não há particularidades ou individualidades, tais quais são conhecidas atualmente.

Portanto, na linha de raciocínio desenhada, não se vislumbra violência conceitual no descarte de indivíduos inservíveis; nem mesmo na retirada da individualidade feminina quanto à decisão da criação, pois liberdade individual

\footnotetext{
4"Os filósofos gregos deixaram a margem de suas reflexões o problema da liberdade e da vontade livre, faltando inclusive, na língua grega, termos correspondentes a uma e a outra. Para Aristóteles, era voluntario o ato não causal, mas desempenhado por um agente em plena posse de sua forca espiritual e física, revestindo-se a liberdade apenas de conteúdo político, traduzindo a condição do homem não-escravo ou da capacidade meramente física factual - a de um homem saudável cujo corpo não estivesse paralisado e fosse capaz de obedecer ao espírito.[...] O preceito que definia o que era de cada um, na pré-modernidade, radicava-se na tradição (Roma) ou nas leis da Natureza (Grécia) ou no mandamento divino (Idade Media) direito natural, consequentemente, antes que direito positivo, direito objetivo, sem duvida, jamais direito subjetivo." PASSOS. Op. cit., p.97.
} 
não há nesse âmbito, nem para homens nem para mulheres, de modo que não se fala em desigualdade social em razão do gênero nesse particular.

\section{2 ÂMBITO FAMILIAR}

A segunda hipótese é aquela que decorre da individualidade humana, mas afeta ao âmbito familiar, cabendo aos pais, em conjunto, a decisão sobre o processo de criação. Nesse caso, a concepção de finalidade social sofre alteração quanto ao caso anteriormente visto.

Se na primeira sociedade a finalidade era o grupo, considerado em sua integralidade, nessa, o fim imediato é a família, compreendida como pequenas sociedades que compõem uma célula maior. A estabilidade social geral depende da manutenção das estruturas menores, ressaltando-se que o rompimento de uma ou outra célula não impõe a destruição de todo o tecido, representando apenas uma mácula a ser reparada.

A questão a ser analisa se localiza no âmbito da composição da decisão dos pais; ou há predominância da vontade de um dele, ou a decisão é composta em conjunto. Na história recente do Brasil ${ }^{5}$, não existia uma composição conjunta quanto à criação. Muitas vezes as sociedades se organizavam pela estrutura paterna (SAHLINS, 1970), expressando o poder patriarcal (PASSOS, 1999), inclusive quanto ao nascimento; momento histórico em que se legalizaram, muitas vezes, situações de violência sexual domiciliar a pretexto de cumprimento dos deveres de conjugais 6 .

Desse modo, essa hipótese não apresenta elementos efetivamente estruturantes da análise da extensão da criação, e, consequentemente, da questão do aborto. Pois, ora o elemento patriarcal determinante ora a impossibilidade de se mensurar a composição da decisão rompem com o ideal de família conceitualmente proposto, enquanto entidade na qual as decisões quanto à

\footnotetext{
${ }^{5} \boldsymbol{C f}$. " Art. 380. Durante o casamento compete o pátrio poder aos pais, exercendo-o o marido com a colaboração da mulher. Na falta ou impedimento de um dos progenitores, passará o outro a exercê-lo com exclusividade. (Redação dada pela Lei $\mathrm{n}^{\circ}$ 4.121, de 27.8.1962). Parágrafo único. Divergindo os progenitores quanto ao exercício do pátrio poder, prevalecerá a decisão do pai, ressalvado à mãe o direito de recorrer ao juiz para solução da divergência." BRASIL. PLANALTO. Lei $\mathbf{n}^{\mathbf{0}}$ 3.071, de $1^{\circ}$ de janeiro de 1916. Disponível em: < http://www.planalto.gov.br/ccivil_03/leis/L3071.htm>. Último acesso: 02 ago. 2016.

${ }^{6 "}$ As relações conjugais são pertinentes à vida conjugal, constituindo direito e dever recíproco dos que casaram. O marido tem direito à posse sexual da mulher, ao qual ela não se pode opor. Casandose, dormindo sob o mesmo teto, aceitando a vida comum, a mulher não se pode furtar ao congresso sexual, cujo fim mais nobre é o da perpetuação da espécie. A violência por parte do marido não constituirá, em princípio, crime de estupro, desde que a razão da esposa para não ceder à união sexual seja mero capricho ou fútil motivo, podendo, todavia, ele responder pelo excesso cometido." NORONHA, E. Magalhães. Direito Penal. 26a . ed. v.3. São Paulo: Saraiva, 2002, p. 70.
} 
criação caberiam igualmente aos pais (independente do gênero que se atribua a essa composição) conjuntamente.

\subsection{LIBERDADE INDIVIDUAL DA MULHER}

A análise da criação sob o fundamento da liberdade individual se deve ao momento pós-moderno vivenciado, no qual, as sociedades, por meio de suas instituições, vivenciam o desafio de garantir a igualdade, reconhecendo a diferença (SANTOS, 2009).

Os Estados que compõem a América Latina, especialmente, passaram a apresentar configurações diferenciadas diante do surgimento de novos agentes, atores e lutas sociais, que requerem pensamentos alternativos para as soluções às reivindicações sociais (Id. Ibid).

Nesse contexto, insere-se a questão da criação humana analisada sob o aspecto da autonomia individual e feminina. A terceira e última hipótese trata da criação como elemento da extensão da liberdade individual da mulher, de modo que, caberia a ela, estritamente, como ser livre e autônomo, a decisão acerca de seu corpo, inclusive no que toca ao processo (inicio, meio e fim) da criação que ocorre em seu âmbito corporal, como extensão de sua individualidade.

A análise dessa hipótese demonstra que a finalidade social, mais uma vez, teve um deslocamento quanto ao objetivo. Agora, o que se destaca e se procura preservar é a individualidade, a liberdade subjetiva. Não mais o grupo ou a família são o fim último do Estado, embora continuem sendo objeto de proteção.

O social é voltado para suprir os ideais individuais de satisfação que apresentam características de urgência. O que pode ser chamado aqui, de modo geral, de dignidade humana ${ }^{7}$. Numa percepção individual do Homem, a sociedade deve refletir esses ideais de preservação individual a fim de refletir os ideais de pertencimento e de auto-reafirmação.

A análise se insere na definição de a quem cabe decidir sobre o corpo de outrem. Considerando-se o outrem como sujeito inserido em uma sociedade autônoma, composta por indivíduos livres e igualmente autônomos.

A criação antes destinada ao grupo, sociedade ou família, agora se dirige para a satisfação individual, enquanto extensão da disposição do próprio corpo. E a mulher é destacada como elemento fundamental, de modo que caberia

\footnotetext{
7"A proclamada igualdade dos homens, sua igual dignidade como pessoa etc. traduz uma intenção, um objetivo a ser alcançado, jamais um dado da realidade. Para se tornar precariamente realidade, reclama empenho permanente, permanente combate travado com nos mesmos e entre nos, individual e socialmente, no sentido de minimizar, sem o aniquilamento de nossa identidade pessoal, os efeitos dissociadores do que nos diferencia.[...] Para se ter direito, basta a forca. Para se ter dever, a ética e imprescindível ." PASSOS. Op. cit., p. 95.
} 
a ela decidir sobre a criação (nascimento, vida e morte), no âmbito de seu corpo, pois a ela pertence o corpo em que se realiza tal processo.

Não se almeja excluir a liberdade individual do homem em buscar meios alternativos legais para concepção, não é esse o objeto do estudo. O que se afasta é a possibilidade de decisão impositiva e contrária à vontade individual de seus destinatários (decisão arbitrária), por meio da sociedade (maioria dominante), quanto ao corpo de parcela de seus integrantes (minoria submetida), retirando dos destinatários o direto e a liberdade de decidir acerca da disposição de seu próprio corpo.

Por liberdade, tem-se a impossibilidade de se impor a outrem, contra a sua vontade, a obrigação inafastável de manter dentro de si a realização de um processo que não deseja, retirando do indivíduo a extensão primaria do conceito de liberdade, que é a disposição de seu próprio eu, psíquico e físico.

$\mathrm{Na}$ análise desse terceiro aspecto, as fases de educação e morte, dois dos elementos da criação, não serão tratados, pois despertam interesses distintos e igualmente relevantes aos homens e às mulheres, e independem de gênero, de modo a requererem especial atenção que não comporta espaço nesse texto.

Também não se está a analisar questões metafísicas ou questões relacionadas ao início biológico da vida. Trata-se da análise da criação sob a perspectiva do ser que cria, e, como nos dois aspectos anteriores, não é o suposto indivíduo a ser criado o objeto de atenção desse texto, mas o ser que cria, que já possui individualidade e liberdade (BYENGTON, 2008) a ser preservada pelo Estado, nos termos dispostos em suas leis máximas. Não se objetiva excluir importância dos temas, simplesmente eles não são objetos desse texto, por opção de corte metodológico.

Volta-se ao elemento da gestação, e, por consequência, ao aborto, enquanto interrupção provocada do processo de gestação, realizada dentro do corpo da mulher. Tal análise, nos moldes propostos no texto, tem relação com a verificação de finalidade social do Estado.

As duas primeiras hipóteses apresentaram resultados considerando a importância social do resultado quanto à criação. No primeiro caso, caberia ao grupo por ser ele o elemento a ser preservado pela sociedade, na segunda, caberia à família, por ser ela o foco de atenção e estrutura da sociedade.

Nesse momento, a individualidade é o centro das atenções. Motivo pelo qual, a hipótese apresenta a mulher como responsável pela decisão do aborto. Essa definição tem conexão com a autonomia individual, no sentido de decisão quanto ao destino do seu próprio corpo. Na acepção de que, o corpo do indivíduo, enquanto atributo de sua liberdade, serve a ele próprio, não podendo ser disposto como coisa, contra a vontade do destinatário, a fim de prover o interesse de outrem, causando ao seu possuidor dano de qualquer natureza. 
A possibilidade de coisificação ou reificação (PASSOS, 1999) do indivíduo, retira-lhe a condição de sujeito de direito e, portanto, de integrante de uma sociedade.

A situação pode ficar mais clara por outra perspectiva exemplificativa, é o caso da liberdade da mulher quanto às vestimentas que ela porta. Se não há uma imposição quanto ao local e as atividades lá desenvolvidas no espaço físico em questão, a cada indivíduo é dado se vestir como bem aprouver a ele. Assim, se fulano (homem ou mulher) gosta de ir à praia de lantejoulas, roupas longas, lenço ou jeans, cabe exclusivamente a ele decidir, pois não existe uma imposição de vestimentas como norma disposta politicamente a todos por meio de lei.

Observe que não se costuma debater acerca das roupas dos homens, quando não há imposição quanto ao local e atividade desenvolvida. Mas, ao revés, há casos em que se debate acerca das roupas das mulheres, em circunstâncias exatamente iguais, discute-se se estão curtas, se devem usar ou não, se tem culpa por dano causado por outrem a sua integridade física, psicológica e moral em razão das roupas que porta.

Ambas as questões, aborto e vestimentas, relacionam-se com a liberdade e a autonomia do indivíduo. Se a liberdade permite que atue de modo a se satisfazer no âmbito do seu próprio corpo, é possível vestir a roupa que lhe aprouver, bem como, interromper processo biológico dentro de seu corpo uma vez que lhe seja desejado.

Em sendo homens e mulheres igualmente indivíduos livres e autônomos a comporem um instituto maior que é a sociedade, na qual se deseja componentes igualmente autônomos. Razão não há para que ambas as liberdades tenham tratamentos distintos. Se motivo inexiste e o tratamento distinto é conferido, temse um desigualamento sem respaldo nos anseios sociais, violador da liberdade e autonomia mínima do ser humano mulher.

$\mathrm{O}$ fato de tais temas serem objeto de debates sociais demonstram a ausência de igualdade entre as diferentes individualidades que compõem a sociedade. O Estado, contramajoritalmente, deve agir para proteger o indivíduo mulher que se encontra subtraído em sua liberdade mínima, que é a disposição de seu corpo, representando a minoria política vulnerável.

$\mathrm{O}$ fato de o aborto se tornar um assunto público demonstra a não definição exata de finalidade da sociedade enquanto grupo e do respeito aos seus integrantes, como iguais e autônomos.

Assim, se a finalidade do grupo social é a preservação das individualidades, não há razão para tratar de maneiras distintas os homens e as mulheres no que respeita à concepção e disposição do próprio corpo.

Concebendo-se que à pessoa humana é garantida a liberdade individual, ela não pode ser submetida à vontade de outrem. Principalmente, à submissão 
física, que traz em si o condão de reduzir o próprio conceito de individuo para o de coisa. As coisas são submetidas, não as pessoas.

\section{CONSIDERAÇÕES FINAIS}

A necessidade de debate acerca de matéria relacionada à autonomia individual, especialmente no elemento primário da liberdade individual, que é a disposição do próprio corpo, representa a maior demonstração de que não há igualdade social, de modo que o discurso-dialógico se faz necessário até o momento em que não mais haverá sentido em realizá-lo, pois a igualdade será uma realidade.

É inócuo falar-se em autonomia social quando não se tem autonomia individual para se decidir discursivamente sobre a sociedade. Trata-se de discurso vazio, construído com premissas falsas. Não se infere autonomia social, sem antes voltar-se para as dificuldades das minorias em suas lutas pelo reconhecimento das individualidades que portam e pela proteção da igualdade de modo a não violentar o que é individual.

Sob o viés da autonomia individual, em sendo a mulher um indivíduo da sociedade e, portanto, merecedora de preservação da individualidade, cabe a ela, exclusivamente, a decisão de interrupção ou não do processo de gravidez. É decisão limitada ao âmbito de seu próprio corpo, sua expressão primeira de liberdade e individualidade.

Destaque-se que essa conclusão tem análise por apenas um aspecto conceitual, o da finalidade a que a sociedade se dedica. Sobre outros aspectos, novos elementos devem ser trazidos à discussão, de modo que a investigação não se esgota aqui, o objetivo do arrazoado é simplesmente apresentar mais um argumento ao debate.

\section{REFERÊNCIAS}

BRASIL. IBGE. Estatística de Gênero. Disponível em: < http://www.ibge.gov. br/apps/snig/v1/?loc=0\&cat=-2,-3,128\&ind=4708>. Acesso em: 06. ago. 2016.

BRASIL. PLANALTO. Lei no 3.071, de $1^{\circ}$ de janeiro de 1916. Disponível em: $<$ http://www.planalto.gov.br/ccivil_03/leis/L3071.htm>. Acesso em: 02 ago. 2016.

BYINGTON. C. A. B. Psicologia Simbólica Yunguiana: a viagem de humanização do cosmos em busca da iluminação. São Paulo: Linear, 2008, p.281-284. 
CARVALHO. C. de O. Mediação Penal não paralela e integrada à justiça restaurativa: uma proposta de efetivação do acesso à justiça no Brasil. Salvador-BA. Dissertação (mestrado) - Universidade Federal da Bahia, Faculdade de Direito, 2014. C331.

CARVALHO, C. O. O Supremo Tribunal Federal e a falácia democrática: proposta de composição e processo. Salvador-BA: Editora Dois de Julho, 2015, p. 41-77.

CASTORIADIS. C. A instituição imaginária da sociedade. Trad. Guy Reynaldi; Rev. tec. Luiz Alberto Salinas Fortes. 3. ed. Coleção Rumos da Cultura Moderna. Rio de Janeiro: Paz e Terra, 1982.

. Figuras do pensável. As encruzilhadas do labirinto. Vol. VI. Trad. Eliana Aguiar. Rio de Janeiro: Civilização Brasileira: 2004.

. Sujeito e verdade no mundo social-histórico. Seminários 19861987: a criação humana. Trad. Eliana Aguiar. Rio de Janeiro: Civilização Brasileira, 2007.

HALL. S. A identidade cultural na pós-modernidade. 10 ed. Rio de Janeiro: DP\&A editora, 2005.

FERREIRA, J. R. Educação em Esparta e Atenas: dois métodos e dois paradigmas. In: LEÃO, D. F.; FERREIRA, J. R.; FIALHO, M. do C.

Cidadania e Paideia na Grécia Antiga. Coimbra, Centro de Estudos Clássicos e Humanísticos da Universidade de Coimbra (CECH), 2010.

GRAMSCI, A. Escritos políticos. Vol. 1. Coleção Universidade Livre. Trad. Manuel Simões. Lisboa: Seara Nova, 1976.

LEAL, R. P. A teoria neoinstitucionalista do processo: uma trajetória conjectural. Coleção Álvaro Ricardo de Souza Cruz. VII vol. Belo Horizonte: Arraes, Editores, 2013.

Processo como teoria da lei democrática. Belo Horizonte: Editora Fórum, 2010.

NORONHA, E. M. Direito Penal. 26. ed. v. 3. São Paulo: Saraiva, 2002.

PASSOS, J. J. C. Direito, poder, justiça e processo: julgando os que julgam. 
Rio de Janeiro: Forense, 1999.

POPPER, K. R. A sociedade aberta e seus inimigos. Trad. Milton Amado. 2 vol. Belo Horizonte: Editora Itatiaia; São Paulo: Editora da Universidade de São Paulo, 1974.

SAHLINS. M. D. Sociedades Tribais. Trad. Yonne Maggie Alves Velho. Rev. Francisca Isabel Vieira. Rio de Janeiro: Zahar Editores, 1970.

SALGADO. E. D. Constituição e democracia. Tijolo por tijolo em um desenho (quase) lógico: vinte anos de construção do projeto democrático brasileiro. Belo Horizonte: Editora Fórum, 2007.

SANTOS. B. de S. Pensar el Estado y la sociedad: desafios actuales. 1. ed. Buenos Aires: Waldhuter Editores, 2009.

SOUZA. W. A. de. Sentença civil imotivada. Salvador: Editora Jus Podivm, 2008 .

\section{WOMEN'S AUTONOMY IN THE LIGHT OF HUMAN CREATION}

ABSTRACT: The issue of abortion requires an extensive analysis involving the participation of the society, since human individuality affects the family and also the autonomy of women, in order to reach the conception of women's individual and legal freedom regarding the matter.

KEYWORDS: Abortion; Family autonomy; Individual autonomy; Social autonomy.

\section{AUTONOMÍA DE LA MUJER A LA LUZ DE LA CREACIÓN HUMANA}

RESUMEN: La cuestión del aborto necesita un análisis amplio que debe involucrar la participación de la sociedad, una vez que la individualidad humana afecta al entorno familiar y la autonomía de la mujer, para así alcanzar la concepción de libertad individual y jurídica de la mujer a respecto del tema.

PALABRAS CLAVE: Aborto; Autonomía familiar; Autonomía individual; Autonomía social. 